\title{
Estimation of Aerodynamic Load on Radome Structure Mounted on Top of a Surveillance Aircraft
}

\author{
S. Ilavarasu, P A Aswatha Narayana, A. C. Niranjanappa
}

\begin{abstract}
The design and development of radome external structure, requires aerodynamic forces acting on it and its distribution. This paper discusses the wind tunnel studies carried out for estimating the incremental effects due to the installation of large ellipsoidal radome along with the support structure pylons on the dorsal side of the fuselage. Effect of locations of radome at $36 \mathrm{~m}$ and $31.5 \mathrm{~m}$ from the nose of the fuselage is discussed. Further using the scan-valve pressure transducer, the pressure distribution on the radome measured at different aerodynamic angles required for the structural design of radome structure is also brought out. Flow visualization study which are useful for qualitative check for the effect of installation of the radome with support structure on the effectiveness of the empennage is attempted.
\end{abstract}

Keywords: Radome, Pressure distribution, Angle of attack, Surveillance

\section{INTRODUCTION}

The development of any surveillance aircraft involves modification in both external to the airframe as well as inside the aircraft cabin. The external modification comprises installation of large antennae inside an oblate ellipsoidal radome with the necessary support structure (pylons) which completely alters the aerodynamic characteristics of the aircraft whereas the inside modification affects only the weight distribution which may be configured in such a way that the center of gravity is within the limits with respect to the basic aircraft. It is imperative to know the incremental effects due to modification on aerodynamic characteristics of the aircraft as well as the aerodynamic loads acting on the radome for the design as well as the support structure. The surveillance aircraft is one of the strategic force multiplier asset of the defence forces of every nation. A suitable platform is identified such that it can be modified and used for the surveillance. It is imperative to check the feasibility of modification on the identified platform from its flight mechanics standpoint that is in terms of performance, stability and control. Once it is identified feasible from the initial analysis, the detailed study on the effect of modification on aerodynamics / flight mechanics is to be attempted by launching multiple campaigns of wind tunnel studies, CFD studies, etc., Radome (Radar \& dome) is an ellipsoidal body mounted on top of the surveillance aircraft using suitable interface structures.

Revised Manuscript Received on February 05, 2020.

* Correspondence Author

S. Ilavarasu, Research Scholar, Department of Aerospace Engineering, Jain University, Bangalore \&

Scientist, Centre for Airborne Systems, DRDO, Bangalore, India

P A Aswatha Narayana, Visiting Professor, IIAEM, Jain University, Bangalore, India.

A. C. Niranjanappa, Scientist, Center for Airborne Systems, DRDO, Bangalore, India.

(C) The Authors. Published by Blue Eyes Intelligence Engineering and Sciences Publication (BEIESP). This is an open access article under the CC BY-NC-ND license (http://creativecommons.org/licenses/by-nc-nd/4.0/)
Radome structure houses antenna and associated electronics for surveillance purposes. Aerodynamic loads at critical design conditions are essential for the structural design of radome. Aerodynamic studies were initiated through wind tunnel tests. The forces on the radome are obtained by wind tunnel tests through incremental approach. The location of the radome on the aircraft is also an important aspect as wakes behind the radome may affect the tail plane. Wind tunnel tests were carried out in open circuit wind tunnel facility at Indian Institute of Science, Bangalore and has 10.5 $\mathrm{m}^{2}$ cross section with the ability to generate wind speed of $50 \mathrm{~m} / \mathrm{s}$. Reynolds number per foot of chord is about 1 million.

\section{WIND TUNNEL MODEL CONFIGURATION}

A 1:18 scale model for surveillance aircraft with suitable interface structure was designed and fabricated [1] in a modular way such that the incremental forces are measured. The model had provisions for mounting a six component strain gauge force balance inside fuselage. The model is held in the test section using a sting that is attached to the sector.

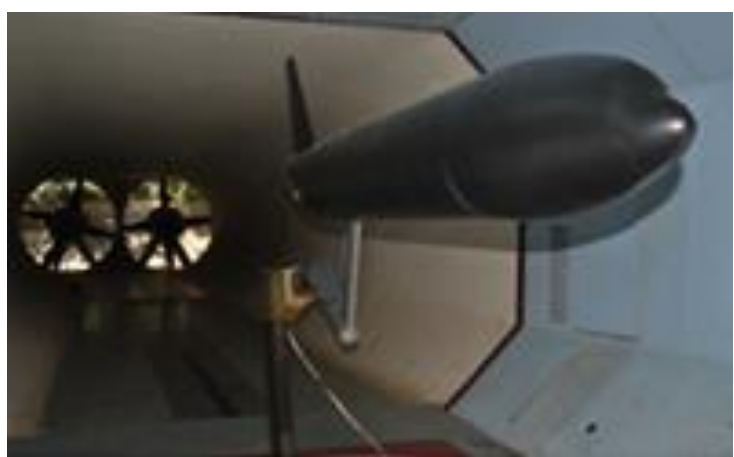

Fig. 1. Basic aircraft

The model had provision for two locations of radome on fuselage also. The wing effect is neglected as the primary objective of the test is to estimate the pressure distribution on radome for the structural design. The effect of wing on the radome would be minimal as the radome is positioned at $6 \mathrm{~m}$ above the wing.

Fig. 1 to 3 show the photograph of different configuration model mounted inside test section. The model configuration is fabricated in modular way to estimate the incremental load [2]. Configuration 1: Basic aircraft (Fuselage \& Vertical fin), Configuration 2: Basic Aircraft \& Pylon, Configuration 3: Surveillance Aircraft (Basic aircraft \& pylon \& radome).

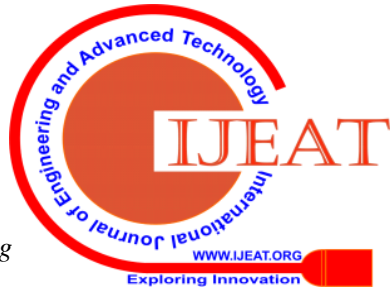




\section{Estimation of Aerodynamic Load on Radome Structure Mounted on Top of a Surveillance Aircraft}

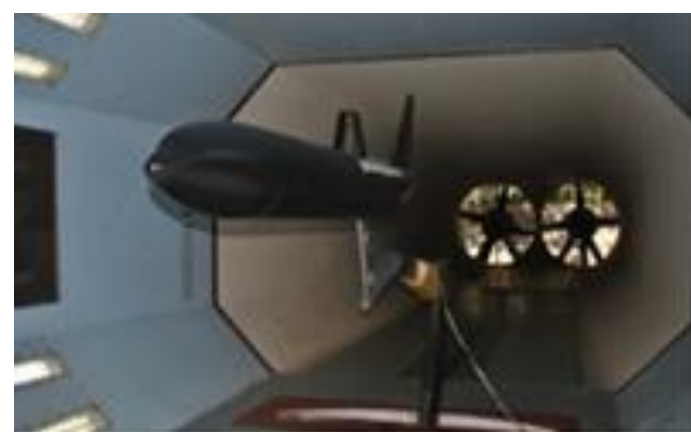

Fig. 2. Basic aircraft \& pylon

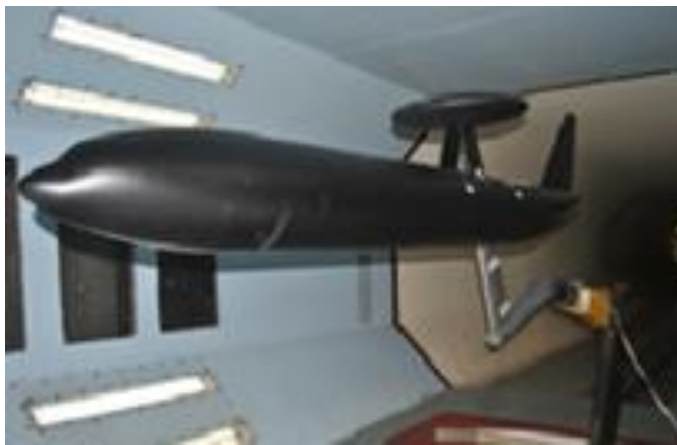

Fig. 3. Surveillance aircraft

For pressure measurements, a total of 460 pressure ports are selected carefully.

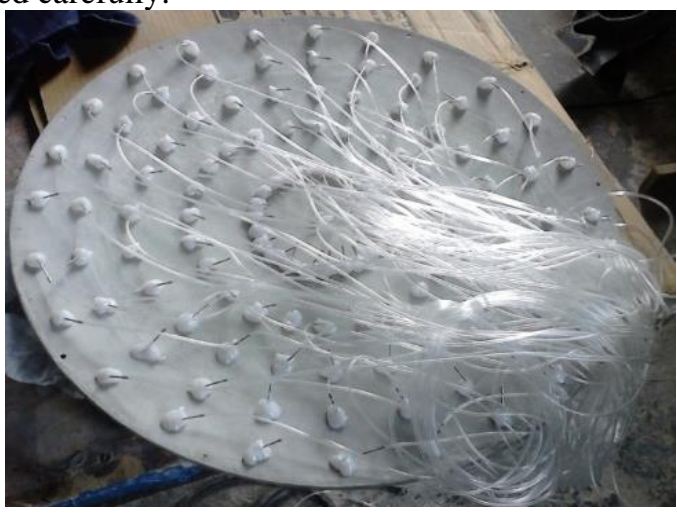

Fig. 4. Pressure port representation

Fig. 4 shows the pressure port representation and distribution. Forward and rear portion of radome are populated with more number of pressure ports. Electronic pressure scanners were used to measure the pressure distribution. The coefficient of pressure is $\left(\mathrm{C}_{\mathrm{P}}\right)$ is computed as below.

$$
C_{p}=\frac{P-P_{r e f}}{q_{\infty}}
$$

where $q_{\infty}$ is the dynamic pressure of air is, $\mathrm{P}_{\text {ref }}$ is reference pressure.

\section{RESULTS AND DISCUSSION}

Aerodynamic coefficients are estimated from the loads measured by the balance, with free stream dynamic pressure, reference area of wing of $1.116 \mathrm{~m}^{2}$ and mean aerodynamic chord of length $0.333 \mathrm{~m}$. The test was carried out at two locations of radome at $36 \mathrm{~m}$ and $31.5 \mathrm{~m}$ from the nose of the fuselage.

The incremental force for different configuration is shown below. The variation of lift coefficient for different configuration is shown in Fig. 5. The lift generated by radome alone is calculated from the coefficient obtained from configuration 3 (C3) to configuration 2 (C2).

$$
\Delta C_{L(\text { radome })}=C 3-C 2
$$

$\Delta \mathrm{C}_{\mathrm{L}}$ is the increment in lift coefficient. The contribution by pylon alone is very marginal and is obtained by subtracting the co efficient from configuration 1 and configuration 2 .

$$
\Delta C_{L(\text { pylon })}=C 1-C 2
$$

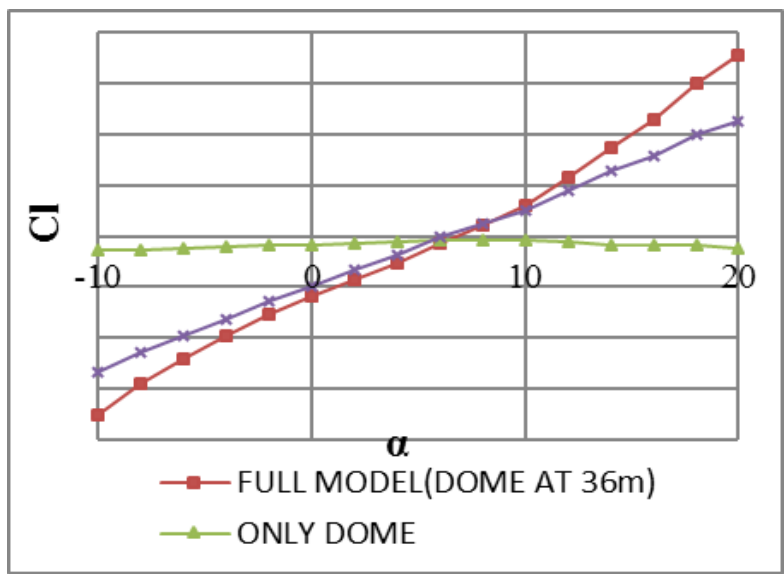

Fig. 5. Variation of lift coefficient for different surfaces at $\quad \boldsymbol{\beta}=\mathbf{0}^{\mathbf{0}}$

The effect of dome location on fuselage is very important, as the dome may affect the effectiveness of vertical fin and also location is important from stability point of view.

Fig. 6 show the variation of lift coefficient $\left(\mathrm{C}_{\mathrm{L}}\right)$ for configuration 3 and contribution of radome alone. The plot clearly depicts the variation of lift coefficient is insignificant up to angle of attack $(\alpha)$ equal to $10^{\circ}$. A marginal variation of lift coefficient is noticed for higher angle of attack.

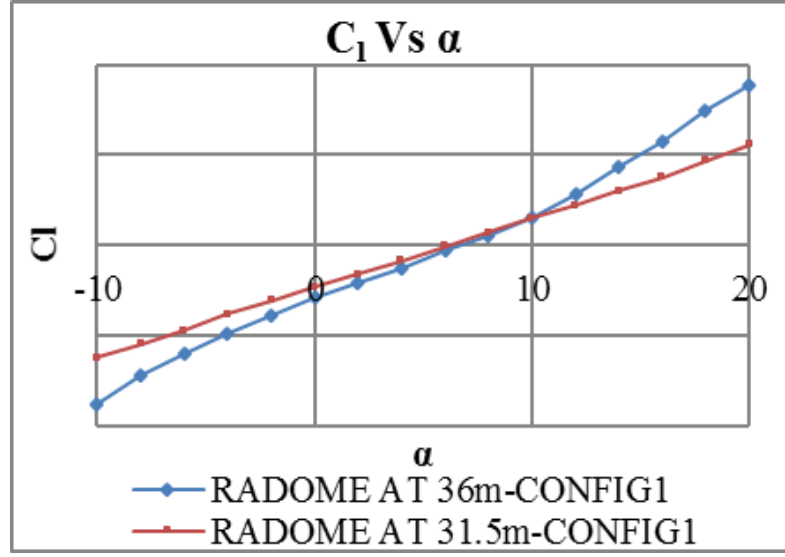

Fig . 6. Variation of lift coefficients at two different positions of radome

Similarly, the variation of drag is marginal with the change in location as seen in Fig. 7. $\mathrm{C}_{\mathrm{d}}$ is coefficient of drag.

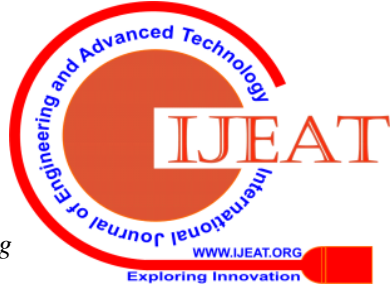




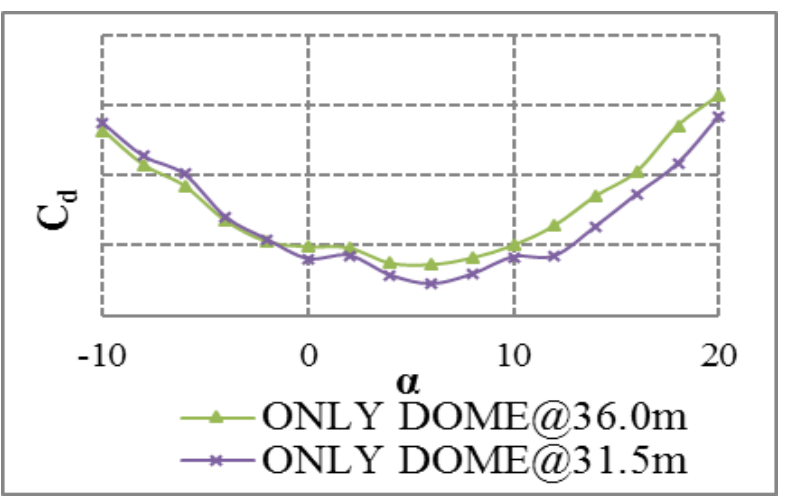

Fig. 7. Drag variation for 2 different locations of radome on fuselage

Fig. 8 shows the variation of drag for different angle of attack and angle of side slip. The minimum drag is noticed for angle of attack of $4^{0}$ to $6^{0}$. This is due to the reason that the dome is kept inclined at $-4^{0}$ with respect to fuselage reference line. It is obvious here that as the angle of attack increases the drag increases and this is due to the reason that radome is projected with higher frontal area. Also the drag increase is noticed as angle of side slip increases. This could be due to the interference of fuselage and pylon.

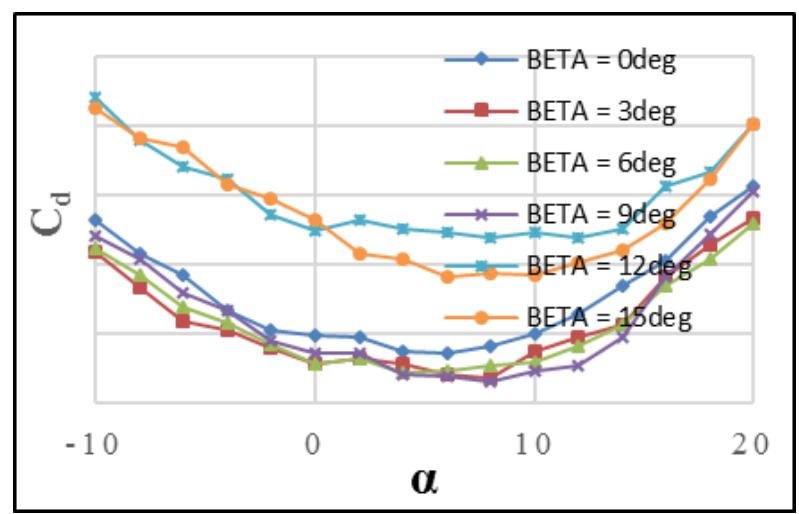

Fig. 8. Variation of drag coefficient with alpha for different angle of side slip

The Side force coefficient (Cy) variation with respect to sideslip angles for different angle of attack for two different locations on fuselage are shown in the Fig. 9. $\beta$ is side slip angle.

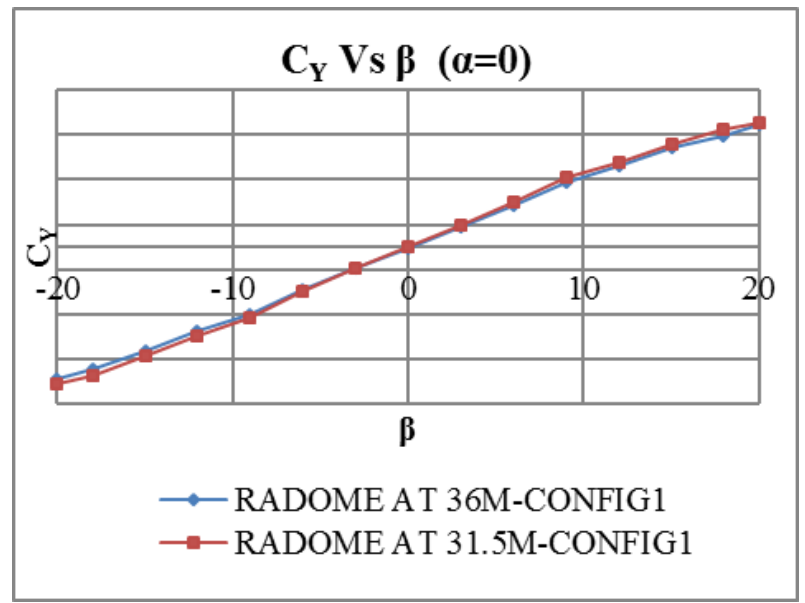

Fig. 9. Variation of side force coefficient for full configuration for radome position at $36 \mathrm{~m}$
The variation of side force with position of radome is very small and can be conveniently neglected

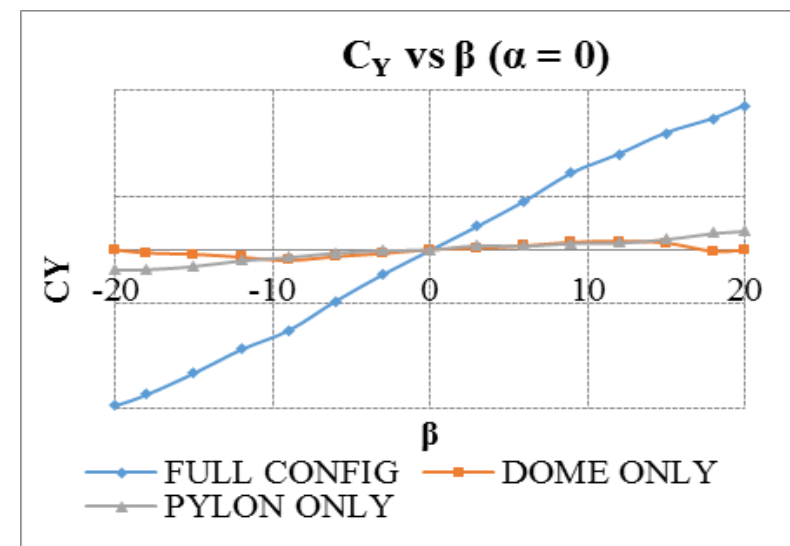

Fig. 10. Variation of side force Coefficient for different surfaces at alpha $=0^{0}$

Fig. 10 shows the variation of side force coefficient for different surfaces for angle of attack at $0^{0}$. Due to the symmetry of the model, the coefficients pass through the origin. The contribution by radome and pylon is small and the main contribution of the side force is due to fuselage.

Fig. 11 to 13 show the variation of pressure for different angle of attack. The red and blue lines of the figure indicate negative and positive relative pressures respectively. The stagnant pressure is seen on the top part of the radome due to the negative incidence of the radome. A cusp is seen on the bottom part of the dome, which is due to the presence of pylon. As the angle of attack increases the stagnation point moves is shifted to the bottom side of the radome.

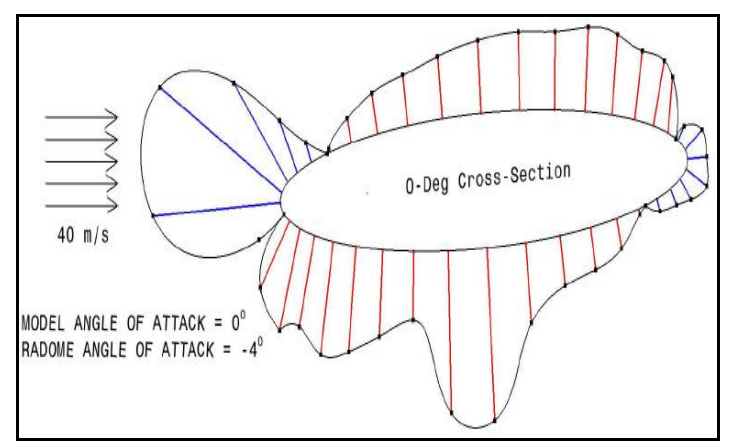

Fig. 11. Cp representation over a cross section $\alpha=0^{0}$

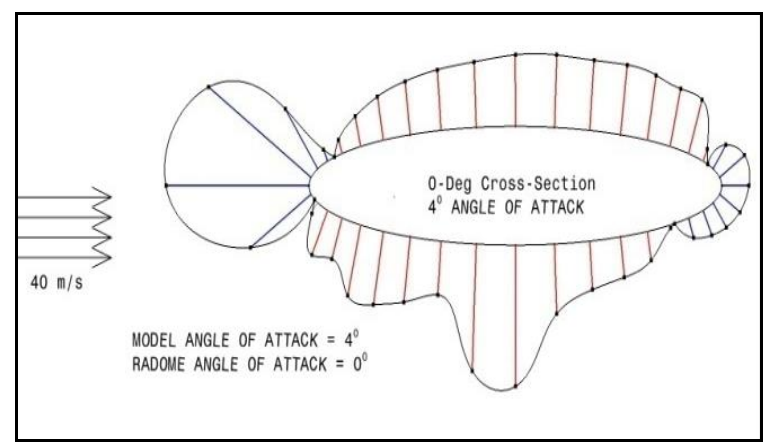

Fig. 12. Cp representation over a cross section $\alpha=4^{0}$

Published By:

Blue Eyes Intelligence Engineering

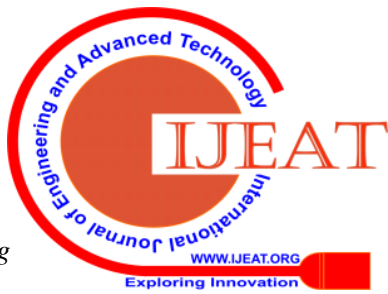




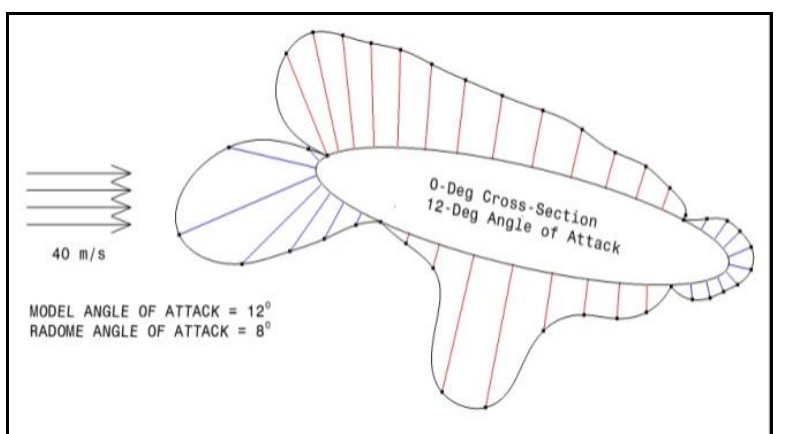

Fig. 13. Cp representation over a cross section $\alpha=12^{0}$

The $\mathrm{Cp}$ variation for $\alpha=0^{0}, 4^{0}, 12^{0}$ for top surface and bottom surface of radome is shown in Fig. 14 \& 15 respectively. A cusp is seen on the bottom portion of the dome, which is due to the presence of pylon. The effect of pylon is clearly seen for all the angle of attack. (Fig. 15).

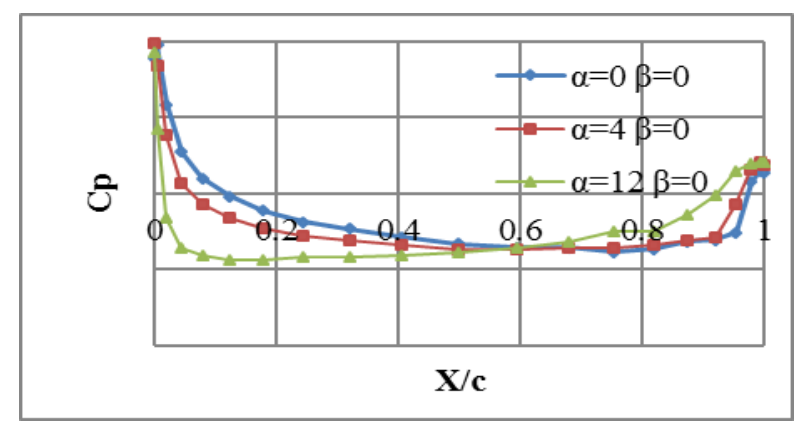

Fig. 14. Variation of $\mathrm{Cp}$ for different angles for top surface

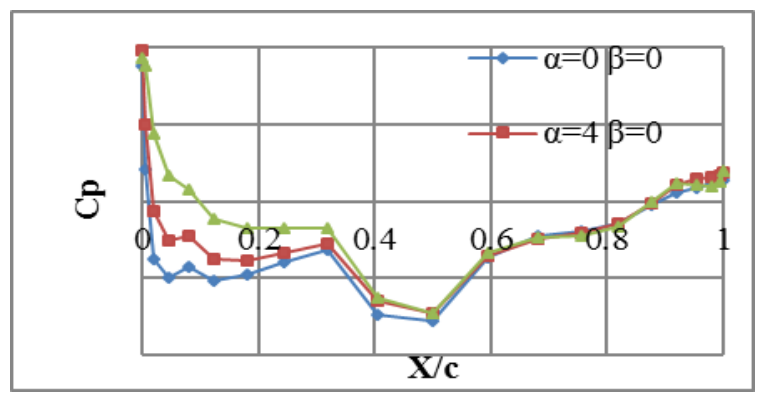

Fig. 15. Variation of $C_{P}$ for different angles for Bottom surface

The coefficient obtained was extrapolated using Prandtl Glauert compressibility correction [3] for higher Mach number. The Prandtl - Glauret transformation is found by linearizing the potential equations associated with compressible, inviscid flow. The correction factor is given by

$$
C_{p}=\frac{C_{p o}}{\sqrt{1-M^{2}}}
$$

$\mathrm{C}_{\mathrm{p}}$ is the compressible pressure coefficient, $\mathrm{C}_{\mathrm{po}}$ is the incompressible pressure coefficient, $M$ is the free stream Mach number. This formula works up to low transonic mach number up to $\mathrm{M}=0.7$.

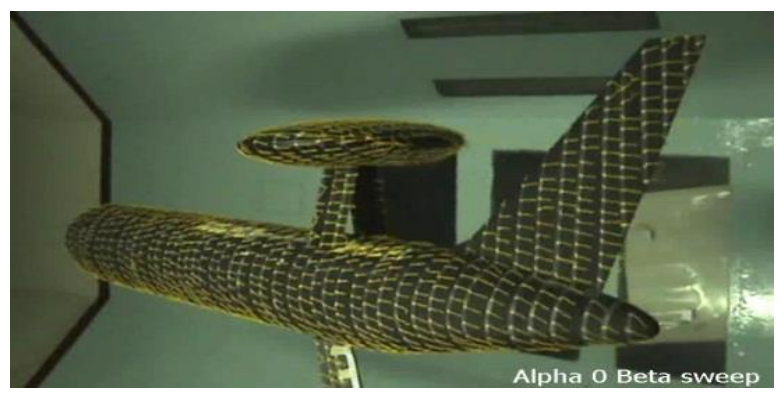

Fig. 16. Flow visualization using tuft technique

Flow visualization using tuft technique [4] was carried out. The model was painted using black with tufts around 850 in numbers are stuck on to it. Tufts selected are cotton number 60 sewing threads cut in to $25 \mathrm{~mm}$ long. Tests are carried out for different aerodynamic angles and visualization effects are video recorded and analyzed. The wakes behind the radome affect the vertical fin and affect the effectiveness of tail plane. This may require additional surfaces to restore directional stability. Further study on this aspect will provide more insights.

\section{CONCLUSION}

Low speed wind tunnel tests have been carried out for range of aerodynamic angles. All the plots display general aerodynamic trend. The data generated is useful for structural design of radome structure of surveillance aircraft. The effect of radome location on fuselage is not affecting the aerodynamic characteristic. Flow visualization study using tuft technique reveals that wakes behind the radome affect the vertical fin and hence affect the effectiveness of tail plane. Positive aerodynamic pressure values act from outside towards inside and negative values act in the opposite direction. In the absence of critical design cases, as a conservative measure extreme pressure (maximum and minimum) values generated for a range of aerodynamic angles is considered for finite element structural analysis of radome.

\section{ACKNOWLEDGMENT}

The authors would like to thank MS Easwaran, Director, CABS and Ms. Suma Varughese, Outstanding Scientist, Program Director, (AEW\&C) for their encouragement and technical supports during the study. The authors are thankful to Mr. Ramanjaneyulu, RV Ramkumar of CABS and V. Surendranath, of IISc, Bangalore for their support during the conduct of test.

\section{REFERENCES}

1. J Dey, V Surendranath, "Low speed wind tunnel studies on a scaled radome on carrier aircraft for surveillance application" IWTR, No 343, 2015

2. S. Ilavarasu, Aerodynamic studies on Airborne Surveillance Aircraft, DRDO science spectrum, 2009.

3. Jewel b. Barlow, William H. Rae, Alan Pope, Low speed wind tunnel testing. 1999, J Wiley

4. John D Anderson, Jr, Fundamentals of Aerodynamics, Fifth edition, McGraw-Hill Series in Aeronautical and Aerospace Engineering. 


\section{AUTHORS PROFILE}

S. Ilavarasu, obtained his M.E (Aeronautical Engineering) degree from Madras Institute of Technology, Chennai and currently pursuing $\mathrm{Ph}$. $\mathrm{D}$ at Jain University Bangalore. Presently he is working as Scientist ' $F$ ' at Center for Airborne Systems (CABS), DRDO, Bangalore. His area of interest includes experimental aerodynamic study on external radome structure for airborne surveillance applications and design of radome structure airborne antenna. His contribution for the present paper is towards design and fabrication of scale down model and conduct of wind tunnel study at low speed wind tunnel facility.

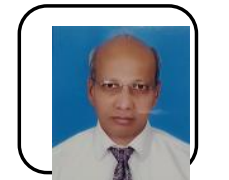

Dr. A C Niranjanappa, obtained his Ph. D from Indian Institute of Science, Bangalore. India. At present he is Group Director and taking care of aircraft operations and mechanical engineering group. His area of interest involves damage characterization of composite radome. His contubution to the present work are arriving at test methodology and analysis of results obtained from the wind tunnel test.

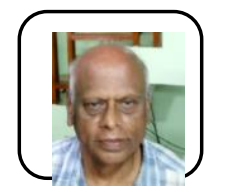

P. A. Aswatha Narayana, obtained his $\mathrm{Ph}$. D from Indian Institute of Technology, Madras. He has served 35 years as professor at Indian Institute of Technology, Chennai. He has published more than 70 papers in international journals $\mathrm{His}$ area of interest includes Computational Fluid Mechanics, Aerodynamics, Flight mechanics. His contribution to the present work are to provide overall guidance to the research team and analysis of the results obtained. 